\title{
PENGARUH PENDIDIKAN KESEHATAN TERHADAP KEAKTIFAN LANSIA DI WILAYAH KERJA PUSKESMAS MANGASA KOTA MAKASSAR
}

\section{Effect of Health Education to Elderly Activity Working in Mangasa Public Health Center, Makassar City}

\author{
Dewi Purnama Windasari ${ }^{*}$, Intan Dwi Astuti \\ Sekolah Tinggi Ilmu Kesehatan Makassar
}

*Korespondensi: dewi.epidpasca@gmail.com

\begin{abstract}
ABSTRAK
Upaya dalam meningkatkan keaktifan lansia dapat dilakukan melalui pendidikan kesehatan, termasuk pencegahan hipertensi pada lanjut usia (lansia) melalui Pendidikan kesehatan. Kota Makassar memiliki jumlah lansia 16,92\% dari total penduduk kota Makassar. Tujuan penelitian ini adalah untuk mengetahui pengaruh pemberian pendidikan kesehatan terhadap keaktifan lansia. Penelitian ini menggunakan desain Quasi Eksperiment yaitu Two Group Postest Only. Penarikan sampel yang digunakan adalah "Purposive Sampling", dengan sampel sebanyak 50 responden. Jumlah sampel pada kelompok eksperimen sebanyaj 25 orang dan kelompok kontrol 25 orang.. Hasil analisis data menggunakan uji-t dengan tingka $\alpha=0,05$, nenunjukkan bahwa ada pengaruh pada keaktifan pada lansia dalam kegiatan posyandu antara kelompok lansia yang telah diberikan dan yang belum diberikan pendidikan kesehatan. Simpulan yang diperoleh terdapat pengaruh keaktifan lansia pada kelompok perlakuan yang diberikan pendidikan kesehatan dan kelompok kontrol di Puskesmas Mangasa. Sebaiknya pemberian pendidikan kesehatan diberikan secara terjadwal dan berkala.
\end{abstract}

Kata kunci: Pendidikan Kesehatan, keaktifan lansia, posyandu

\section{ABSTRACT}

Efforts to increase the activity of the elderly can be generate, including the prevention of hypertension in the elderly group through health education. Makassar City has several elderly people $16.92 \%$ of the total population of Makassar City. The purpose of this study was to see the effect of offering health education on the activeness of the elderly. This study used a Quasi-Experiment design, namely Two Group Posttest Only. The sampling used was "purposive sampling", with a sample of 50 respondents. The number of samples in the experimental group was 25 people and the control group 25 people. The results of the data analysis used the t-test with a level of $\alpha=0.05$, indicating that there was an effect on the activeness of the elderly in Integrated Pos Service activities between the elderly groups who had been given and those who had not. given health education. The conclusion obtained is that there is an effect of elderly activity in the treatment group that is given health education and the control group at the Mangasa Community Health Center. We recommend that you provide health education that is given regularly and periodically.

Keywords: Health education, elderly activity, Posyandu. 


\section{PENDAHULUAN}

Lanjut usia merupakan seseorang baik berjenis kelamin perempuan maupun laki - laki yang telah berusia 60 tahun ke atas yang memiliki karakteristik sosial masyarakat yang menunjukkan tanda fisik seperti rambut yang memiliki uban, kerutan pada kulit, dan berkurangnya gigi (Windasari, 2014).

Berdasarkan data WHO, Jumlah penduduk lansia mengalami pertambahan yang cukup pesat dan cepat terlebih pada negaranegara Asia (Mengko, Kandou, \& Massie, 2015). Angka penduduk akan mengalami kenaikan dan dirasakan oleh penduduk usia yang masih produktif, jika ditambah dengan angka ketergantungan penduduk usia remaja yang kurang dari 15 tahun, dimana saat ini jumlah penduduk kurang dari 15 tahun sebesar 29,13\%.\% (Martono, 2011).

Menurut laporan BKKBN pada tahun 2013 yang telah dipublish adalah data Lansia di Sulawesi Selatan sebanyak 91.487 jiwa (17,11\% dari jumlah penduduk Sul-Sel), dan sementara untuk Kota Makassar terlapor memiliki jumlah lansia sebanyak 38.410 jiwa atau $16,92 \%$ dari total penduduk (Arsyidik, 2016).

Data Puskesmas Mangasa Kota Makassar, terkait data lansia yang telah memperoleh perawatan dan pelayanan kesehatan di wilayah puskesmas sebanyak 2.652 lansia. Pelayanan posyandu merupakan salah satu tempat pelayanan kesehatan dimasyarakat yang memiliki peran aktif masyarakat melalui pengembangan UKBM.
Keberadaannya sangat diperlukan untuk penerapan dalam upaya promosi dan pencegahan di kalangan masyarakat (Dinkes Kota Makassar, 2014).

Menurut penelitian Novayenni, menjelaskan bahwa untuk meningkatkan jumlah kunjungan lansia ke posyandu lansia maka perlu dilakukan pendidikan kesehatan. Dengan adanya pendidikan kesehatan akan mempengaruhi pengetahuan lansia akan manfaat posyandu lansia sehingga dapat menambah kunjungan lansia. Menurut WHO menekankan bahwa pentingnya pendidikan kesehatan untuk mendukung pemenuhan pelayanan kesehatan dan promosi kesehatan bagi lansia. Pendidikan kesehatan dapat meningkatkan pengetahuan seseorang akan kesehatan dan menjaga kesehatan serta membuat seseorang mendapatkan informasi tentang pilihan dalam menjaga kesehatan (Novayenni, 2015).

Berdasarkan temuan peneliti yang telah dilakukan dilapangan dengan menggunakan metode wawancara pada kader posyandu lansia di RW 5 Kelurahan Mangasa, kader posyandu menjelaskan pelaksanaan kegiatan di posyandu masih terdapat lansia yang kurang aktif dalam mengikuti kegiatan - kegiatan yang diberikan tenaga kesehatan. Dari sasaran hanya beberapa yang aktif dan ikut serta kegiatan yang dilaksanakan posyandu. Dari 10 orang diantaranya terdapat 6 orang yang memiliki riwayat penyakit darah tinggi atau yang biasa lebih dikenal dengan hipertensi. Untuk meningkatkan keaktifan para lansia, sehingga 
http://journal.unpacti.ac.id/index.php/JPP

perlu diberikan pemberian informasi dalam bentuk pendidikan kesehatan tentang hipertensi dan upaya untuk mencegah penyakit menjadi semakin parah. Berdasarkan uraian permasalahan sehingga membuat peneliti ingin melakukan penelitian terkait pengaruh pemberian pendidikan kesehatan terhadap adanya perubahan keaktifan pada lansia untuk mengikuti kegiatan Posyandu di wilayah kerja Puskesmas Mangasa.

\section{BAHAN DAN METODE}

Jenis penelitian yang digunakan dalam penelitian ini yaitu Eksperimen, desain eksperimen semu (quasi eksperiment designs). Penelitian yang model rancangannya berupa Postest Only Two Group, dengan menggunakan uji-t. Populasi sebanyak 57 orang, dengan sampel sebanyak 50 responden yang telah dibagi menjadi dua kelompok sebanyak 25 orang tiap kelompoknya dan menggunakan purposive sampling.

\section{HASIL}

\section{Karakteristik Responden}

Dari Tabel 1 menunjukkan bahwa jumlah keseluruhan responden yaitu sebanyak $50(100 \%)$ orang, terdapat dua kelompok responden yaitu kelompok responden Kontrol sebanyak 25 (50\%) orang dan kelompok responden eksperimen sebanyak 25 (50\%) orang. Pada tabel diatas distribusi frekuensi dengan kategori jenis kelamin yang paling banyak pada kedua kelompok kelompok adalah perempuan yaitu sebanyak 19 orang $(76,0 \%)$, dan 21 orang $(84,0 \%)$.

Tabel 1. Distribusi Karakteristik di Wilayah Kerja Puskesmas Mangasa

\begin{tabular}{|c|c|c|}
\hline Variabel & $\mathbf{n}$ & $\%$ \\
\hline \multicolumn{3}{|l|}{$\begin{array}{l}\text { Jenis Kelalmin } \\
\text { (Kontrol) }\end{array}$} \\
\hline Laki-Laki & 6 & 24,0 \\
\hline Perempuan & 19 & 76,0 \\
\hline \multicolumn{3}{|l|}{$\begin{array}{l}\text { Jenis Kelamin } \\
\text { (Eksperimen) }\end{array}$} \\
\hline Laki-Laki & 4 & 16,0 \\
\hline Perempuan & 21 & 84,0 \\
\hline \multicolumn{3}{|l|}{$\begin{array}{l}\text { Tingkat Pendidikan } \\
\text { (Kontrol) }\end{array}$} \\
\hline Tidak Sekolah & 5 & 20,0 \\
\hline SD & 15 & 60,0 \\
\hline SMP & 3 & 12,0 \\
\hline SMA & 2 & 8,0 \\
\hline \multicolumn{3}{|l|}{$\begin{array}{l}\text { Tingkat Pendidikan } \\
\text { (Eksperimen) }\end{array}$} \\
\hline Tidak Sekolah & 4 & 16,0 \\
\hline SD & 11 & 44,0 \\
\hline SMP & 6 & 24,0 \\
\hline SMA & 4 & 16,0 \\
\hline \multicolumn{3}{|l|}{ Jumlah Lansia } \\
\hline Kontrol & 25 & 50,0 \\
\hline Eksperimen & 25 & 50,0 \\
\hline \multicolumn{3}{|l|}{$\begin{array}{l}\text { Pekerjaan Lansia } \\
\text { (Kontrol) }\end{array}$} \\
\hline IRT & 13 & 64,0 \\
\hline Wiraswasta & 3 & 12,0 \\
\hline Tidak Ada & 6 & 24,0 \\
\hline \multicolumn{3}{|l|}{$\begin{array}{l}\text { Pekerjaan Lansia } \\
\text { (Eksperimen) }\end{array}$} \\
\hline IRT & 16 & 56,0 \\
\hline Wiraswasta & 6 & 24,0 \\
\hline
\end{tabular}

Sumber: Data Primer, 2018

Pada kategori tingkat pendidikan diperoleh hasil bahwa responden yang paling banyak yaitu pada pendidikan SD baik pada kelompok Kontrol dan kelompok perlakuan, memiliki jumlah yang sama sebanyak 15 orang (60,0\%). Distribusi frekuensi pekerjaan lansia 
http://journal.unpacti.ac.id/index.php/JPP

untuk Kontrol dan Eksperimen menunjukkan hasil bahwa responden yang paling banyak pada kategori pekerjaan sebagai IRT yaitu 13 $(64,0 \%)$ dan $16(56,0 \%)$ (Tabel 1).

\section{Analisis Univariat}

Tabel 2. Distribusi Responden Berdasarkan Keaktifan Lansia

\begin{tabular}{lcc}
\hline \multicolumn{1}{c}{ Responden } & $\mathbf{n}$ & $\mathbf{\%}$ \\
\hline Kelompok Kontrol & & \\
$\quad$ Aktif & 6 & 24,0 \\
Tidak aktif & 19 & 76,0 \\
Kelompok & & \\
Eksperimen & & \\
Aktif & 18 & 72,0 \\
Tidak aktif & 7 & 28,0 \\
Jumlah & 25 & 100,0 \\
\hline
\end{tabular}

Sumber: Data Primer, 2018

Berdasarkan tabel 2 diperoleh responden pada kelompok Kontrol lebih banyak pada kategori tidak aktif sebanyak 19 (76\%) dan lebih sedikit pada kategori aktif sebanyak 6 orang $(24,0 \%)$. Pada kelompok eksperimen dengan kategori aktif yang paling banyak mengikuti kegiatan posyandu yaitu sebanyak 18 orang $(72,0 \%)$ dan kategori tidak aktif yang paling sedikit mengikuti kegiatan posyandu sebanyak 7 orang $(28,0 \%)$.

\section{Analisis Bivariat}

Berdasarkan hasil tabel 3 diperoleh nilai $\mathrm{t}$ hitung sebesar 3,795 $<\mathrm{t}$ tabel dan nilai signifikansi $0,000<0,05$, sehingga peneliti menemukan terdapat pengaruh antara pendidikan kesehatan terhadap keaktifan lansia dalam kegiatan posyandu. Berdasarkan ouput coefficients diketahui bahwa niai koefisien regresi variable keaktifan lansia adalah sebesar $-0,480$ bernilai negative, sehingga dapat dikatakan bahwa pendidikan berpengaruh negative terhadap keaktifan lansia, dimana semakin rendah pendidikan lansia, maka akan menurun pula keaktifan lansia di posyandu.

Tabel 3. Pengaruh Pendidikan kesehatan Terhadap Keaktifan Lansia

\begin{tabular}{lccccc}
\hline \multirow{2}{*}{ Keaktifan Lansia } & $\mathbf{n}$ & \multicolumn{2}{c}{$\begin{array}{c}\text { Mean value } \\
\text { Keaktifan lansia }\end{array}$} & t-test & \multirow{2}{*}{$\mathbf{p}$ value } \\
\cline { 2 - 4 } & & Aktif & Tidak aktif & & \\
\hline Kontrol & 25 & 1,75 & 1,27 & \multirow{2}{*}{3,79} & $\mathrm{p}=0,000$ \\
Eksperimen & 25 & & & & \\
\hline
\end{tabular}

Sumber: Data Primer, 2018

\section{PEMBAHASAN}

Penelitian ini dilakukan dengan mengisi lembar observasi setelah dilakukannya pemberian pendidikan kesehatan pada responden. Hasil yang dianalisis, beberapa variabel yaitu jenis kelamin, tingkat pendidikan, pekerjaan sebagai karakteristik responden.

\section{Karakteristik Responden}

Menurut Hardy winoto dan setiabudhi (2015) terkait variabel dengan kategori usia mempunyai pengaruh yang cukup besar pada 
tingkat pengetahuan dan serta kemandirian lansia, seseorang yang memiliki usia yang lebih tua maka akan semakin banyak dan tinggi pengetahuannya dan tetapi sebaliknya akan semakin rendah atau mengalami penurunan kemungkinan tingkat kemandirian pada lansia tersebut. Hal ini juga erat kaitannya pada lansia baik dari segi pengalaman, ataupun pada derajat status kesehatannya dalam melakukan kegiatan sehari - harinya.

Untuk kategori jenis kelamin pada responden terlihat bahwa perempuan lebih banyak pada saat penelitian. Kondisi ini sama dengan data laporan dari Badan Pusat Statistik (2012) yang mengemukakan jumlah lansia yang terdapat di Negara Indonesia untuk data jenis kelamin yaitu laki-laki pada tahun 2011 sebanyak 9.290.782 jiwa dan perempuan bsebanyak 11.256.759 jiwa

Kategori tingkat pendidikan terakhir pada responden penelitian baik dari kelompok eksperimen ataupun pada kelompok kontrol didapatkan hasil, sama-sama lebih banyak yang pendidikan terakhirnya SD (Sekolah Dasar). Pendidikan yang dimiliki oleh responden merupakan faktor penunjang yang sangat penting yang dapat mempengaruhi pengetahuan yang dimiliki oleh responden.

Perlu diperhatikan bahwa seseorang yang memiliki pendidikan yang rendah akan semakin sulit menerima sebuah informasi pendidikan terkait kesehatan. Terjadi penambahan pengetahuan tidak harus hanya diperoleh dari segi formal, tetapi seseorang juga dapat memperoleh pendidikan dari non formal, contoh yang biasa diberikan dalam hal ini adalah salah satunya penyuluhan kesehatan yang dapat kita golongkan dalam pendidikan non formal (Wigati, 2011)

Pekerjaan pada responden penelitian, diperoleh hasil yaitu responden pada kelompok eksperimen dan pada kelompok control samasama lebih banyak yang bekerja pada kategori sebagai IRT. Dalam hal ini pekerjaan selalu dikaitkan dengan status ekonomi dan pendapatan seseorang yang sangat memberikan pengaruh besar pada kemampuan membeli barang keluarga untuk memenuhi kebutuhan sehari-hari.

Jika pendapatan keluarga lebih tinggi akan lebih mudah dalam daya beli dan lebih mudah untuk memperoleh informasi kesehatan tentang penyakit tidak menular salah satunya penyakit degeneratif, jika dibandingkan dengan keluarga yang status ekonominya rendah. Lingkungan tempat bekerja juga dapat menjadi media untuk memperoleh berbagai informasi salah satunya tentang kesehatan.

\section{Pendidikan Kesehatan terhadap Keaktifan Lansia}

Berdasarkan hasil analisis uji-t nilai $p$ sebesar $0,000<0,05$, sehingga diketahui bahwa Ho ditolak, dimana memiliki perbedaan antara kelompok lansia yang telah diberikan pendidikan dan yang belum diberikan pendidikan di Posyandu wilayah kerja Puskesmas Mangasa.

Tarigan (2011) dalam penelitiannya mengemukakan bahwa dalam pemberian metode ceramah memiliki beberapa 
keterbatasan, sehingga dalam pemberian informasi sebenarnya dapat digabungkan penggunaannya dalam metode ceramah dan metode pelatihan ataupun metode lainnya sehingga disebut sebagai metode ceramah bervariasi.

Notoadmodjo (2007), menjelaskan pada bagian metode diskusi yang digunakan dalam metode pemberian konseling untuk meningkatkan metode ceramah. Ketika memberikan informasi utamanya kesehatan seharusnya tidak bersifat searah saja, akan lebih baik jika dua arah yang diterapkan ada respon yang diperoleh. Sehingga pengetahuankesehatan sebagai dasar dari perilaku seseorang akan secara mantap dalam penerapannya dan sangat mudah untuk dipahami.

Lain halnya dengan Tarigan (2011) yang mengatakan bahwa pendidikan kesehatan dengan pemberian metode diskusi akan memiliki hasil pengetahuan dapat meningkat lebih tinggi dan baik jika dibandingkan dengan hanya menggunakan metode konseling serta metode ceramah disebabkan pada saat melakukan berdiskusi rata - rata peserta konseling akan lebih berperan aktif dalam mengkontruksi pengetahuan mereka sendiri.

Berdasarkan hasil penelitian ini sehingga peneliti juga memiliki asumsi yang sama bahwa ketika adanya metode yang digabung (metode diskusi dan ceramah) yang juga ditunjang dengan penyediaan alat bantu berupa yaitu media flip chart dan leaflat sangat diharapkan dari hasil konseling dapat memberikan hasil yang lebih maksimal, karena dengan metode ini terdapat dua indera yang turut berperan aktif selama kegiatan berlangsung yaitu indera pendengaran dan indera penglihatan juga, disamping itu responden juga dapat berpartisipasi secara langsung, sehingga dapat dilihat terdapat perbedaan hasil pada saat pemberian post test antara kelompok eskperimen dan control.

Dari uraian tersebut bahwa hasil yang diperoleh adalah, dengan pemberian metode ceramah dan diskusi pada proses pemberian pendidikan serta ditunjang dengan alat bantu berupa media flip chart serta leaflet, akan sangat berpengaruh terhadap tingkat praktik keaktifan lansia pada saat proses kegiatan berlangsung. Sebagaimana tujuan peneliti yaitu untuk memperoleh perubahan pengetahuan serta terbentuknya perilaku yang sehat salah satu indikatornya yang ddiukur adalah perubahan perilaku, indikator yang dapat dinilai yaitu peningkatan pengetahuan (Fitriani, 2011).

Hasil penelitian ini ternyata juga searah dengan temuan penelitian Eni Kusyati (2006) yang menyebutkan terdapat perbedaan hasil antara keakifan kader sebelum dan sesudah pemberian perlakuan yaitu memberikan pendidikan/penyuluhan kesehatan tentang posyandu lansia. Bukan hanya dari segi keaktifan ikut serta kegiatan yang dilaksanakan posyandu lansia tidak semata-mata dipengaruhi oleh pendidikan kesehatan, multi faktor yang juga memberi peranan adalah jarak rumah dari posyandu, dukungan keluarga, sikap yang kurang menyenangkan dan tidak ramah terhadap petugas posyandu dan sarana 
prasarana.

Menurut peneliti bahwa terdapat pengaruh keaktifan lansia dalam ikut serta kegiatan puskesmas baik kelompok perlakuan maupun kelompok kontrol di wilayah kerja puskesmas Mangasa. Setelah pemberian pendidikan kesehatan diperoleh peningkatan pengetahuan pada lansia. Hal ini menegaskan bahwa dengan ikut serta menghadiri beberapa kegiatan - kegiatan posyandu, lansia akan memperoleh pendidikan dan penambahan informasi tentang cara hidup sehat, dan akan terjadi pembentukan sikap yang akan mendorong minat lansia untuk selalu mengikuti kegiatan yang dilaksanakan posyandu.

\section{KESIMPULAN DAN SARAN}

Berdasarkan hasil penelitian dapat ditarik kesimpulan yaitu ada perbedaan pada keaktifan lansia di kegiatan posyandu pada wilayah kerja Puskesmas Mangasa. Dan terdapat pengaruh pendidikan kesehatan terhadap keaktifan lansia dalam kegiatan posyandu di wilayah kerja Puskesmas Mangasa.

Sebaiknya tenaga kesehatan agar lebih aktif memberikan informasi baik secara door to door atau penyuluhan, dilakukan secara berkala. Peneliti selanjutnya sebaiknya dapat meneliti pretes dan postes pengetahuan tentang hipertensi, dan juga dapat melihat pola makan serta pola aktivitas pada lansia.

\section{UCAPAN TERIMA KASIH}

Peneliti ingin menyampaikan ucapan terima kasih kepada Ketua dan Civitas Kampus
Sekolah Tinggi Ilmu Kesehatan Makassar, Kepala Puskesmas Mangasa, dan mahasiswa yang turut membantu menyelesaikan penelitian ini.

\section{DAFTAR PUSTAKA}

Bandiyah S, 2009, Lanjut Usia dan Keperawatan Gerontik. Nuha Medika, Yogyakarta.

Dinkes Kota Makassar. 2014. Profil Kesehatan Kota Makassar. Dinas Kesehatan Kota Makassar

Erpandi. 2015. Posyandu Lansia: Mewujudkan Lansia Sehat, Mandiri \& Produktif. EGC, Jakarta.

Hesthi, Wahono. 2010. Analisis Faktor-Faktor yang Mempengaruhi Pemanfaatan Posyandu Lansia Di Gantungan Makam haji. Fakultas Ilmu Kesehatan Universitas Muhammadiyah, Surakarta. https://ejournal.unisayogya.ac.id/ejourna 1/index.php/JHeS/article/view/439

Hidayat, Aziz. 2012. Riset Keperawatan dan Tehnik Penulisan Ilmiah. Salemba Medika, Jakarta.

Hidayat, Aziz. 2007. Metode Penelitian Keperawatan dan Teknik Analisis Data. Salemba Medika, Jakarta.

Hutabarat, Christina. 2012. Studi Kualitatif Pemanfaatan Posyandu Lansia Di Wilayah Kerja Puskesmas Sarudik Kabupaten Tapanuli Tengah. Fakultas Kesehatan Masyarakat, Depok http://lib.ui.ac.id/file?file=digital/20355 560-S-

Christina\%20Novalina\%20Hutabarat.pd f

Khoiriyah, Nurul. 2011. Faktor yang Berhubungan dengannMotivasi Lansia Berkunjung ke Posyandu Lansia di RW II Kelurahan Margorejo Kecamatan Cepiring Kabupaten Kendal. Universitas 
http://journal.unpacti.ac.id/index.php/JPP

Muhammadiyah Semarang

Martono, Heru. 2011. Lanjut Usia dan Dampak Sistemik Dalam Siklus Kehidupan. Depok https://www.stikesdutagama.ac.id/asset/f iles/JURNAL_DOSEN_2016

Puspitasari, Dian. 2014. Hubungan Tingkat Pengetahuan dan Dukungan Keluarga Dengan Keaktifan Lanjut Usia Dalam Mengikuti Kegiatan Posyandu Lansia Desa Gajahan Kecamatan Colomadu. Fakultas Ilmu Kesehatan Universitas Muhammadiyah, Surakarta. http://eprints.ums.ac.id/30908/

Rahmita, Dkk. 2015. Pengaruh Pemberian Pendidikan Kesehatan Terhadap Angka Kunjungan Lansia Ke Posyandu Lansia. Riau

https://onesearch.id/Record/IOS1766.art icle-

5174? widget $=1 \&$ repository_id $=1766$

Pawenrusi, dkk. 2017. Pedoman Penulisan Skripsi. Edisi 14. STIK Makassar, Makassar.

Sigalingging, Ganda. 2011. Sosial Ekonomi Keluarga Lansia terhadap Pemanfaatan Posyandu Lansia Di wilayah Kerja Puskesmas Darussalam Medan. Universitas Sumatera Utara, Medan http://repository.usu.ac.id/handle/12345 $6789 / 30560$

Suseno, Dian. 2012. Faktor yang Mempengaruhi Keaktifan Lansia Dalam Mengikuti Kegiatan Posyandu Lansia Di Desa Kauman Kecamatan Polanharjo Kabupaten Klaten. Fakultas Ilmu Kesehatan Universitas Muhammadiyah, Surakarta. http://eprints.ums.ac.id/20530/

Viena, Dkk. 2015. Pemanfaatan Posyandu Lansia di Wilayah Kerja Puskesmas Teling Atas Kota Manado. Universitas Sam Ratulangi, Manado. https://ejournal.unsrat.ac.id/index.php/ji $\mathrm{kmu} /$ article/view/7856

Windasari, Dewi Purnama. 2014. Pengaruh Senam Lansia Terhadap Perubahan Tekanan Darah Penderita Hipertensi Lansia Di Beberapa Puskesmas Kota Makassar. Universitas Hasanuddin, Makassar. http://digilib.unhas.ac.id

Wigati, Putri. 2011. Pengaruh Pendidikan Kesehatan tentang Penyakit Degeneratif Terhadap Keaktifan Lansia dalam Kegiatan di Posyandu Lansia Krida Dharma Wreda Kelurahan Jrebes. Universitas Sebelas Maret, Surakarta. https://digilib.uns.ac.id/ 